\title{
Improvement of the Ground-Fault Detection in Field Windings of Synchronous Machines with Static Excitation based on Third-Harmonic Voltage Phase-Angle Comparison
}

\author{
Francisco R. Blánquez, Carlos A. Platero, E. Rebollo and F. Blázquez
}

\begin{abstract}
This paper presents the theoretical approach and experimental tests of a new algorithm for detecting ground faults in rotor windings of synchronous generators with static excitation. This location method requires the installation of a grounding resistance in the secondary winding of the excitation transformer. First, the third-harmonic reference voltage is obtained by the voltage measurements in the excitation system. Then, the third-harmonic voltage at the grounding resistor is compared to the reference voltage. The ground fault is detected when the phase angle between those voltages is under the trip setting value. This new algorithm has been tested in a 5 kVA Synchronous generator with satisfactory results.
\end{abstract}

Keywords: Faults, Diagnostics, Synchronous Motors, Excitation System, Fault handling strategy.

\section{Introduction}

Protective systems of power plants are a primary concern not only to provide safety conditions to the power plant personnel, but also to maintain the reliability of the power network. In power plants the generating unit is the most important element; therefore, the modern protective systems focus specially on it [1]. The ground fault in the field winding is one of the most common failures of synchronous generator, mostly when the end of its lifetime is close.

The excitation field circuit of synchronous generators is typically isolated during normal operating conditions. The field winding is exposed to mechanical and thermal stress cycles due to the rotation speed and the temperature rise [2]. Additionally, the field winding can be exposed to abnormal mechanical or thermal stress due to over-speed, vibrations [3], excessive field currents or poor cooling, among some others. It may result in a breakdown of the insulation between the field winding and the rotor iron. Since the excitation system is isolated, a single ground fault in the field winding, or its associated circuits, causes a negligible fault current. Therefore, it does not represent any immediate danger. However, if a second ground fault occurs, high fault currents and severe mechanical unbalances may arise quickly, leading to serious damage in the generator. In some cases the field current, flowing through the rotor iron, could generate enough heat to melt it [4]. It is essential, therefore, that the first insulation failure has to be detected [5], and the generator has to be removed from service in order to check the insulation health [6].

The field of fault detection in synchronous generators is a very active research topic, and many contributions have been published recently related to it [7]-[10]. Typically, for the detection of rotor ground faults, some commercial detection devices can be used. All of them precise an external injection voltage source. They are based on the detection of the current provided by the source in case of ground fault. For synchronous generators with static excitation, a novel ground-fault detection algorithm was presented [11], [12], which only requires a high-value grounding resistance to be connected to the neutral point of the excitation transformer. This technique is based in the supervision of the thirdharmonic component of the voltage measured in the grounding resistance. In case of ground fault in the field winding, the level of this harmonic component increases over the setting value, and the fault is 
detected. This detection method also discriminates between a ground fault in the AC, or DC side of the excitation system, because in case of ground fault in the AC side, only fundamental-frequency component appears in the voltage measurement at the grounding resistance.

On the other hand, the ground fault location is usually a costly and laborious process. Typically, the location of the field-winding ground faults requires the generator to be removed from service, and the rotor to be extracted, which is commonly a costly operation. After the rotor extraction, the ground-fault location is performed in standstill condition, requiring high-power external power source and a highsensibility voltmeter [13].

A novel location algorithm has been presented [14], [15] which implies two major advantages. Firstly, it does not need an additional voltage source; secondly, this new technique locates the defect in on-line operation. This location algorithm also requires a high-value grounding resistance to be connected to the neutral point of the excitation transformer. It is based in the linear relationship between the DC component of the voltage measurement at the grounding resistor, and the position of the fault along the field winding. The amplitude of the DC component has the maximum value, with positive polarity, when the fault occurs in the negative terminal, and negative polarity when the fault occurs in the positive terminal. The DC component is negligible for faults at the midpoint of the winding.

However, this location method may be affected by the rotor capacitance, as observed during field tests in a large-size synchronous generator. In healthy condition, there was an unexpected voltage $\mathrm{V}$, measured in the grounding resistor. The presence of this voltage during healthy condition is caused by the effect of the capacitance-to-ground of the rotor. This voltage has a high magnitude and a fundamental frequency of $150 \mathrm{~Hz}$, would implies (in the AC-DC discriminating algorithm [13]) a fault in the field winding. Moreover, this voltage has no DC component, which implies (in the location algorithm [14]) a fault at the $501 \%$ of the field winding. This fact may make the location algorithm vulnerable to provide unwanted trip commands caused by the effect of the rotor capacitance, while the machine is in healthy conditions.

This paper presents the theoretical approach and experimental tests of a new algorithm for detecting ground faults in synchronous machines with static excitation. This algorithm allows detecting the ground fault at any point of the field winding without the use of any additional equipment or external voltage source. This is performed by the analysis of the phase angle between a third-harmonic voltage, obtained from the excitation measurements, and the third-harmonic component of the voltage measurement at the grounding resistor. This algorithm also allows distinguishing the cases of ground fault in the rotor winding, from the cases of high influence of the rotor capacitance in healthy condition, which represents a remarkable improvement of the previous method.

\section{Theoretical Approach for the Analysis of the Static Excitation System}

The static excitation system is composed by an excitation transformer, the field winding and the controlled rectifier. This converter is controlled by the Automatic Voltage Regulator (AVR) of the power plant. In Fig. 1 (a), the excitation transformer is represented as a three-phase voltage source with its series reactance. A ground fault has been represented in point $x$ of the winding, with a value of fault resistance $R_{f}$. The value of $\mathrm{x}$ goes from 0 (negative terminal) to 1 (positive terminal). The field winding is represented by several "pi" equivalents in series connection. Each "pi" equivalent is composed by a series inductance $L_{r}\left(L_{R} / n\right)$, and two parallel capacitors $C_{r}\left(C_{R} / 2 n\right)$. The series resistance and capacitance is neglected due to its considerably low value.

This complex circuit can be simplified, taking into account the following consideration. The harmonic decomposition of the voltages between the neutral point, $\mathrm{N}$, and each terminal of the field winding, Positive $(100 \%)$ and Negative $(0 \%), V_{p N}$ and $V_{n N}$, respectively. These voltages correspond to the output voltage of a half-bridge rectifier, as observed in Fig. 1 (b). The field voltage $\left(V_{f}\right)$ and its harmonic components $\left(V_{f D C}\right.$ and $\left.V_{f A C, 6 f}\right)$ are also shown in the same figure, just to compare with the others waveforms. While the DC component of $V_{p N}$ and $V_{n N}$ has inverse polarity $\left(V_{p N D C}\right.$ and $\left.V_{n N D C}\right)$, the third harmonic component of both voltages is identical $\left(V_{p N A C, 3 f}\right.$ and $\left.V_{n N A C, 3 f}\right)$. Both $V_{p N}$ and $V_{n N}$ remain inalterable during a ground fault in the field winding, and so its third-harmonic components 

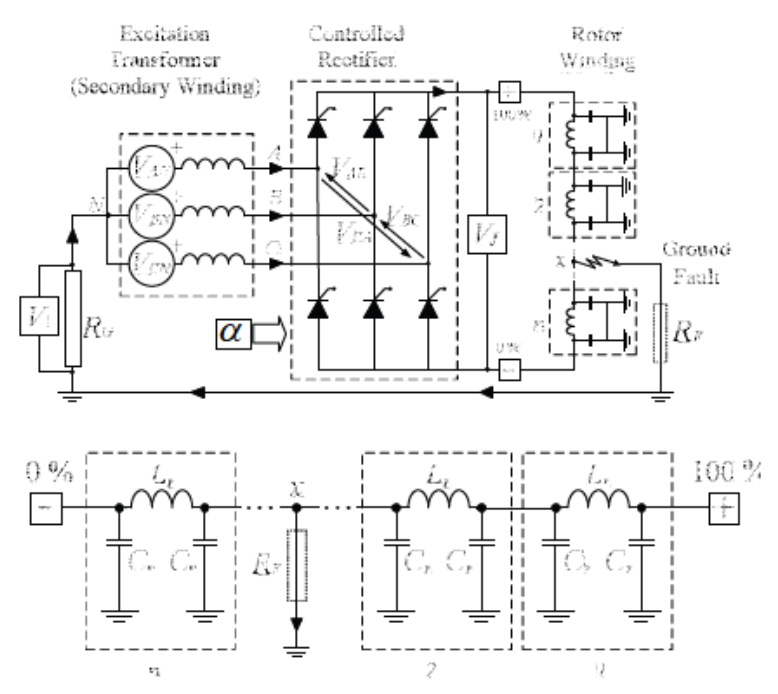

(a)
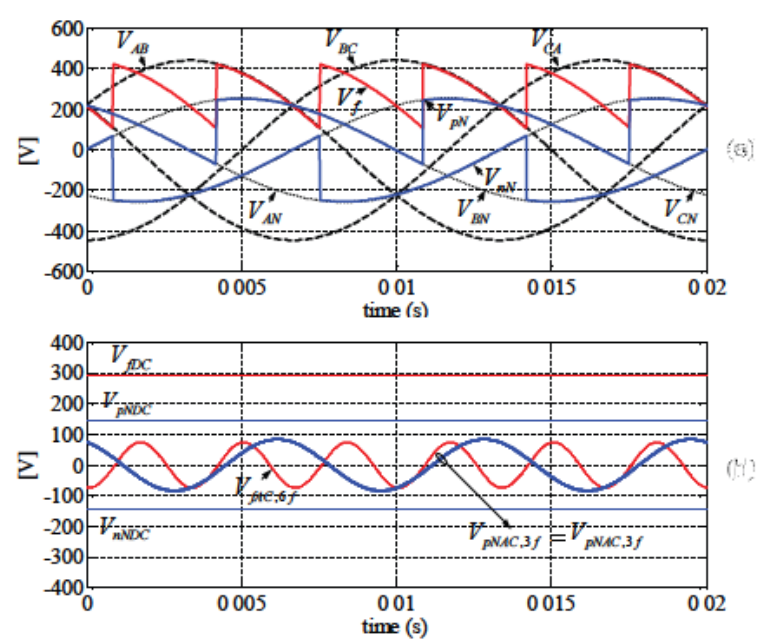

(b)

Fig. 1: Simplified schema of a static excitation system of a synchronous machine.

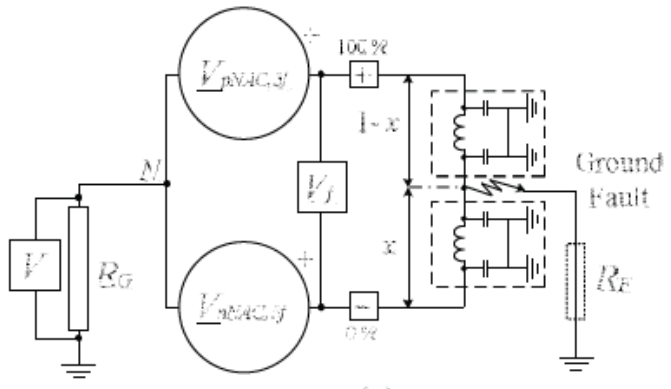

(a)

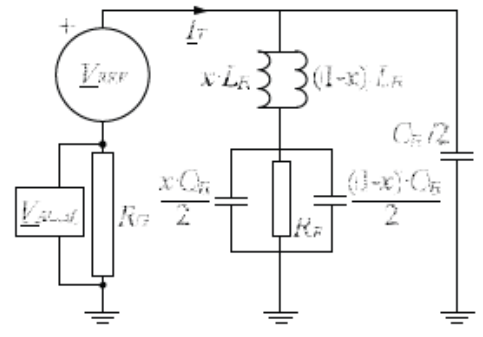

(i)

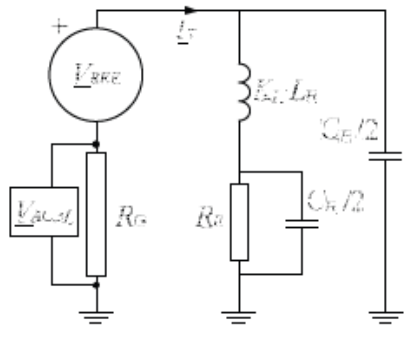

(c)

Fig. 2: Simplified schema of a static excitation system of a synchronous machine.

$V_{P N A C, 3 f}$ and $V_{n N A C, 3 f}$. Therefore, any of these latter variables can be used a reference voltage $\left(V_{R E F}\right)$. This fact leads to the equivalent circuit shown in Fig. 2 (a), where the components of the system between the neutral point, $\mathrm{N}$, and both terminals have been replaced by two voltage sources with value $V_{p N A C, 3 f}$ and $V_{n N A C, 3 f}$.

Accordingly, only for the third-harmonic equivalent circuit, both terminals can be connected, and therefore the equivalent circuit can be considerably simplified (Fig. 2 (b)). This circuit can be simplified once more as shown in Fig. 2 (c), where

$$
K_{L}=x \cdot(1-x)
$$

As can be seen, in the equivalent circuit depends on the characteristics of the field winding $\left(L_{R}\right.$ and $\left.C_{R}\right)$, the fault resistance $R_{F}$, the fault location $x$, and also on the value of grounding resistance $R_{G}$. Depending on the value of these variables the equivalent impedance is different.

From the equivalent circuit of the system, the phase angle is obtained theoretically (1). This expression allows to evaluate the phase angle not only for a ground fault of any fault-resistance value, but also for the case of healthy conditions.

$$
\varphi=\tan ^{-1}\left(\frac{D_{1} \cdot \omega \cdot\left(D_{2} C_{R}^{\prime} R_{F}^{2}-L_{R}^{\prime}\right)}{D_{1}\left(R_{G}+R_{F}\right)+\omega^{2}\left(R_{F} C_{R}^{\prime} D_{2}\right) \cdot\left(L_{R}^{\prime}+R_{F} R_{G} C_{R}^{\prime} D_{2}\right)}\right)
$$

where 


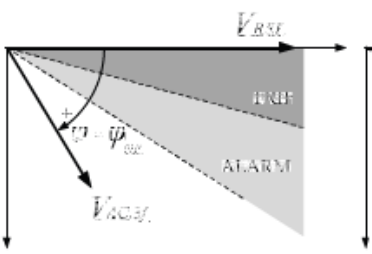

(a)

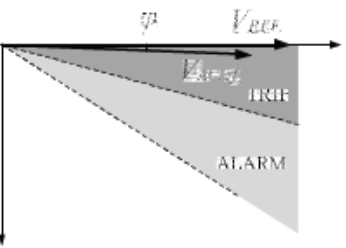

(b)

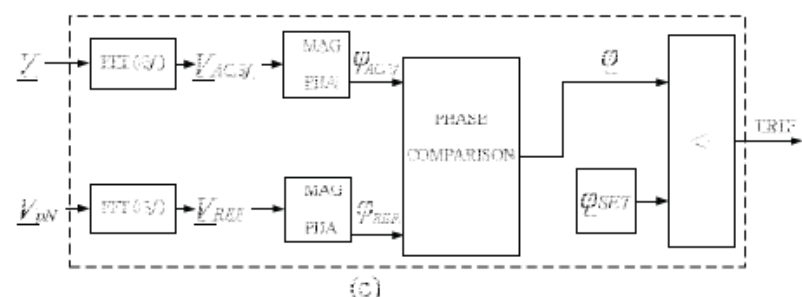

Fig. 3: (a) Phasor comparison at healthy condition $\left(R_{F} \approx \infty\right)$; (b) Phasor comparison in case of a ground fault; (c) Ground fault detection algorithm.

$$
\begin{gathered}
L_{R}^{\prime}=K_{L} \cdot L_{R} \\
C_{R}^{\prime}=C_{R} / 2 \\
D_{1}=1-\omega^{2} L_{R}^{\prime} C_{{ }^{\prime}}{ }^{\prime} \\
D_{2}=2-\omega^{2} L_{R}^{\prime} C_{R}^{\prime}
\end{gathered}
$$

Particularizing expression (2) for generators in which $\omega^{2} L_{R}^{\prime} C_{R}^{\prime}$ is very low, some simplified and useful expressions can be obtained. In healthy conditions, the phase angle is positive and has a high value, which depends on the capacitance-to-ground of the field winding, and the grounding-resistance value, as observed in (2).

$$
\varphi_{N F}=\lim _{R_{F} \rightarrow \infty} \varphi \approx \tan ^{-1}\left(\frac{1}{\omega R_{G} C_{R}}\right)
$$

On the other hand, if there is a solid ground fault, the value of the phase angle is zero, or even negative if the inductance of the field winding is considerably high.

$$
\varphi_{F}=\lim _{R_{F} \rightarrow 0} \varphi \approx \tan ^{-1}\left(\frac{-\omega K_{L} L_{R}}{R_{G} D_{1}}\right)
$$

The values of $L_{R}$ and $C_{R}$ are defined by the installation and they are typically provided in the datasheet of the synchronous generator. The value of $x$ and $R_{F}$ are unknown variables. Finally, the value of $R_{G}$ can be considered as a design parameter.

\section{Algorithm of rotor-winding ground-fault detection based in voltage-phasor comparison}

For healthy condition, the value of $R_{F}$ is very high $\left(R_{F} \approx \infty\right)$, therefore, the equivalent impedance angle will depend on $L_{R}$ and mostly on $C_{R}$. See equation (5). For solid ground faults, the equivalent impedance will be purely resistive (if the fault is at terminals, $x=0 \mathrm{pu}$ or $x=1 \mathrm{pu}$ ) or slightly inductive if the fault is in the inner part of the field winding. The phase angle between $V_{R E F}$ and the equivalent current $\left(I_{T}\right)$, $\varphi$, can be obtained as well by the angle between $\mathrm{V}_{R E F}$ and $V_{A C, 3 f}$, which is the third harmonic component of voltage $V$, measured in the grounding resistor. Therefore, for healthy condition, the phase angle between $V_{R E F}$ and the equivalent current $\left(I_{T}\right), \varphi$, is positive and high $\left(\varphi_{N F}\right)$. See Fig. 3 (a). For a solid ground fault this angle decreases dramatically (See Fig. 3 (b)) to zero or even to a low but negative value $\left(\varphi_{F}\right)$. Then, the phase angle $\varphi$ can be used to detect the ground faults.

The block diagram of the detection algorithm is shown in Fig. 3 (c). Firstly, the third-harmonic component of $V_{p N}\left(V_{R E F}\right)$ and of $V\left(V_{A C, 3 f}\right)$ are obtained by a Fourier filter. Then, the phase angle of $V_{R E F}$ and $V_{A C, 3 f}$ are obtained. The phase angle between both voltages $\varphi$ is calculated considering $\varphi_{R E F}$ the reference. Finally, the angle $\varphi$ is compared to the threshold $\varphi_{\text {SET }}$. If $\varphi$ is under the setting value, then the ground fault is detected. 


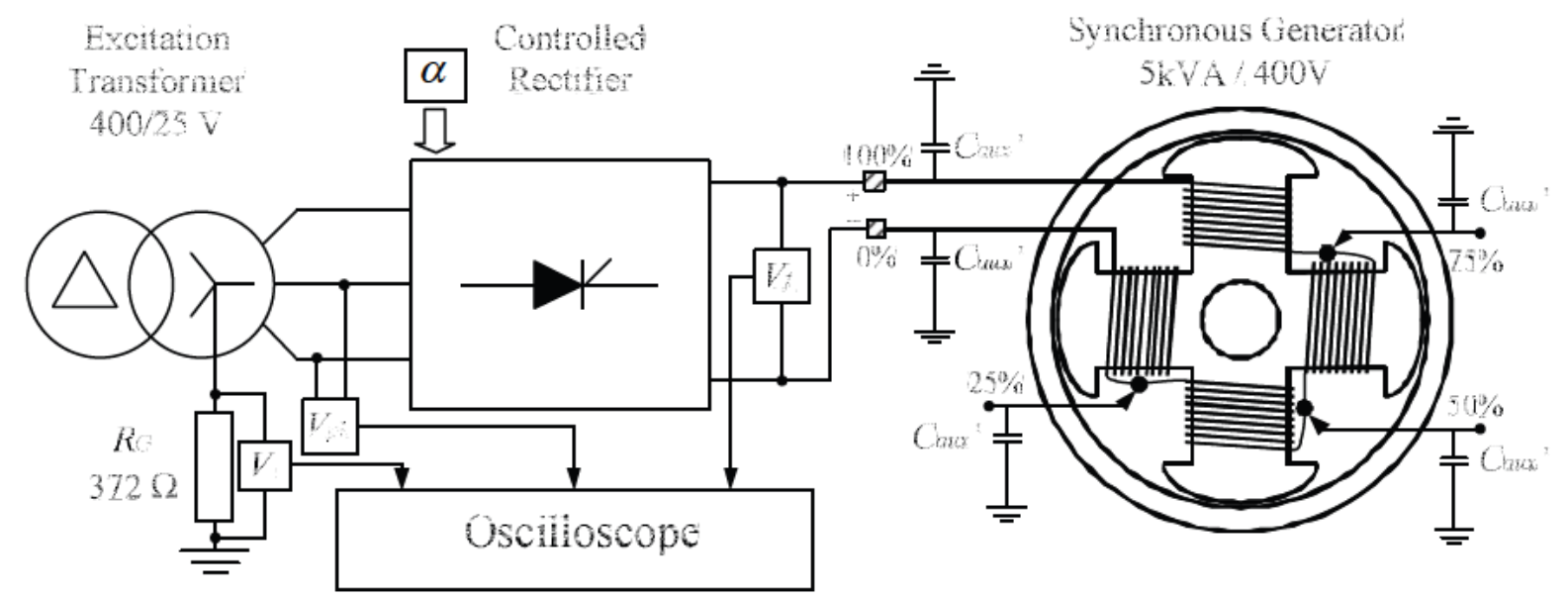

Fig. 4: Simplified diagram of the experimental setup.

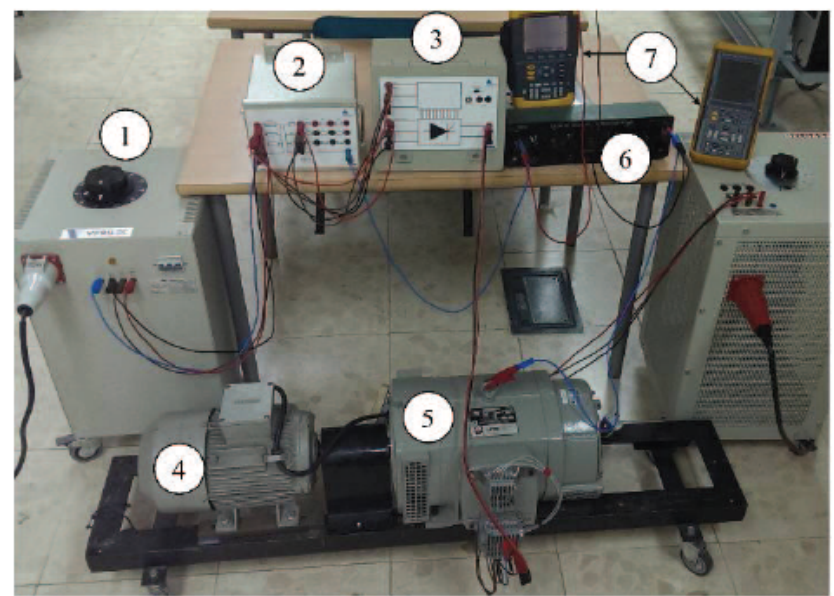

Fig. 5: Picture of the experimental setup, where (1) is the power supply, (2) the excitation transformer, (3) the controlled rectifier, (4) the induction motor (prime mover), (5) the synchronous generator, (6) the grounding resistor, and (7) the oscilloscopes.

\section{Experimental results}

The presented ground-fault detection algorithm has been tested in a 400V 5kVA synchronous generator. This generator is specially design for testing ground faults since its field winding has 3 accessible points at $25 \%, 50 \%$ and $75 \%$ of the field winding. See Fig. 4 . Of course, ground faults can also be tested in both negative $(0 \%)$ and positive terminal $(100 \%)$ of the winding. Its static excitation system is composed by a $400 / 25 \mathrm{~V}$ excitation transformer and a controlled rectifier, and the grounding resistance value is $372 \Omega$. As the field winding of the synchronous machines of this size have insignificant capacitance to ground, additional capacitors have been added to each accessible point of the field winding.

The ground faults were conducted at each accessible point of the winding, for several values of fault resistance. The voltage measurements, indicated in Fig. 4, were registered by an oscilloscope and postanalyzed with Matlab, were the detection algorithm is executed. In Fig. 5, a picture of the experimental setup is shown. 
(a)
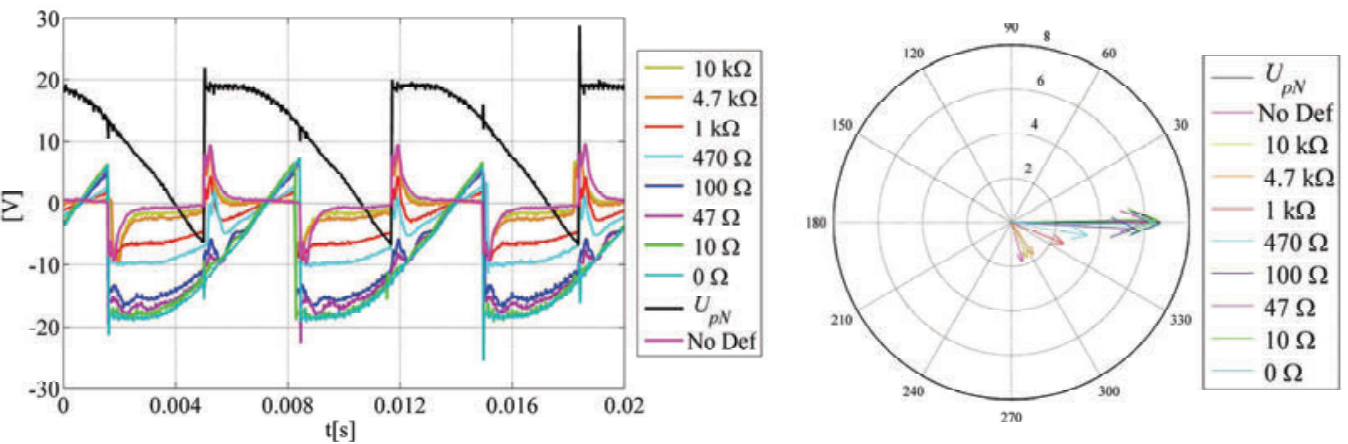

(b)

(c)
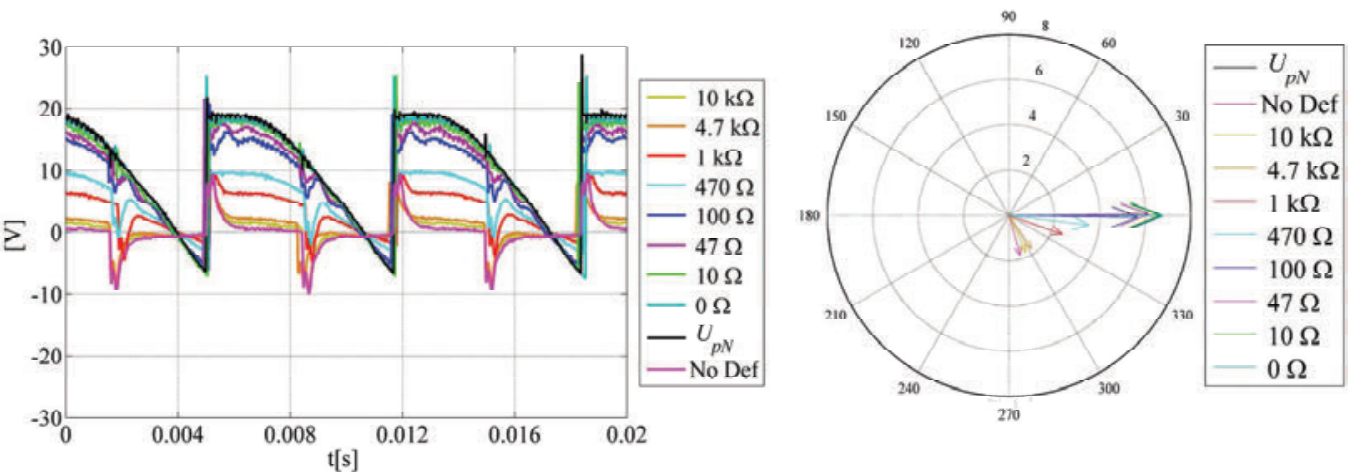

(d)

Fig. 6: Results of ground fault with several values of fault resistance. (a) Waveform of voltages for ground fault at $0 \%$; (b) phasor representation for ground fault at $0 \%$; (c) Waveform of voltages for ground fault at $100 \%$; (d) phasor representation for ground fault at $100 \% . C_{R}=1 \mu \mathrm{F}$.

(a)
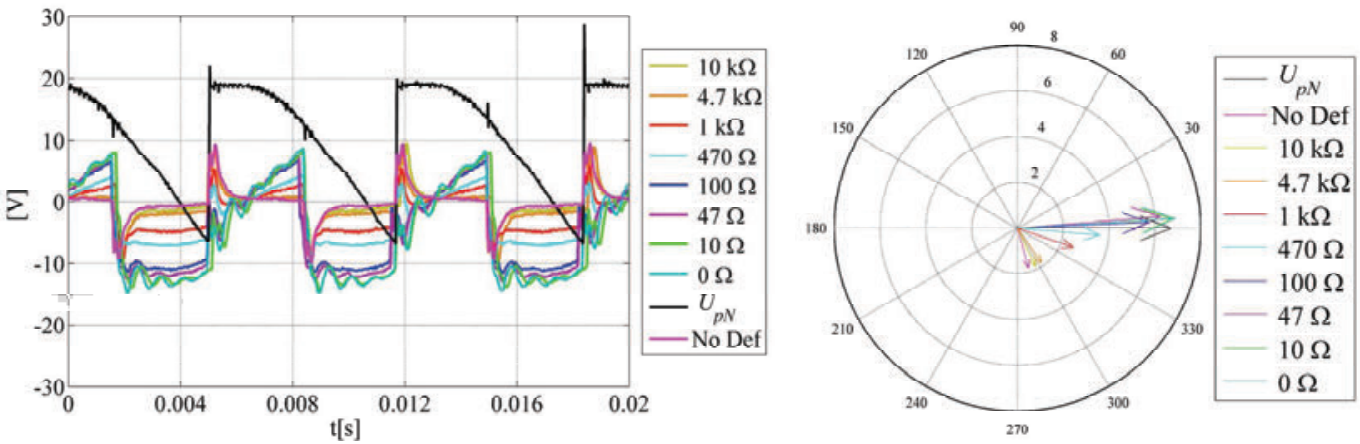

(b)

(c)
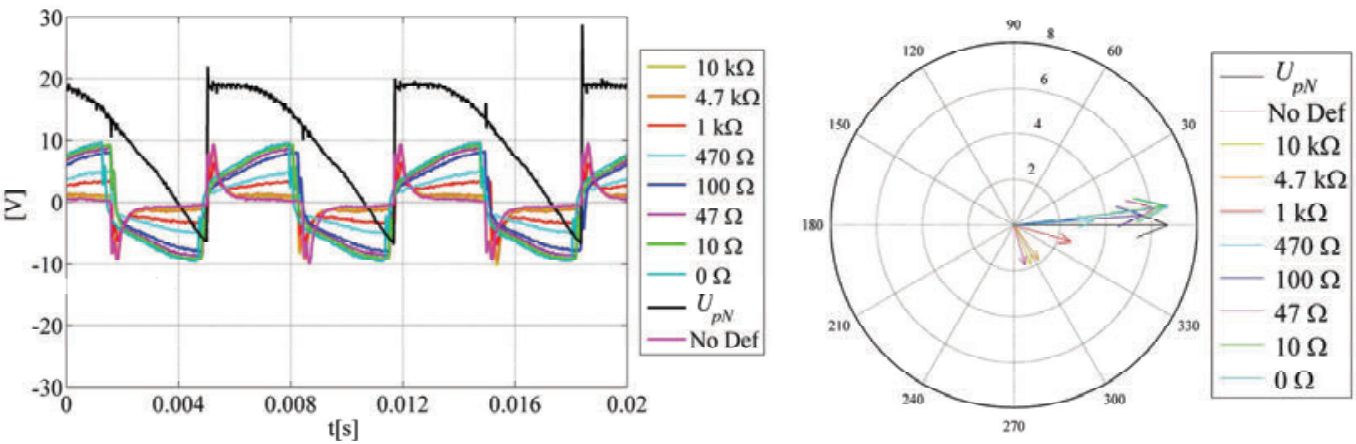

(d)

Fig. 7: Results of ground fault with several values of fault resistance. (a) Waveform of voltages for ground fault at 25\%; (b) phasor representation for ground fault at 25\%; (c) Waveform of voltages for ground fault at $50 \%$; (d) phasor representation for ground fault at $50 \% . C_{R}=1 \mu \mathrm{F}$. 


\section{Results with additional capacitance of $1 \mu \mathrm{F}$}

In Fig. 6, the results of ground fault at $0 \%$ and $100 \%$ are shown. At observed, at healthy condition, both waveform are the same (No Def), however, as the value of fault resistance decreases, the waveform is distorted. In case of ground fault at $0 \%$ the waveform of $V$ becomes $V_{n N}$ (Fig. 6 (a)), while in case of ground fault at $100 \%$ the waveform of $V$ becomes $V_{p N}$ (Fig. 6 (c)),. Although those waveforms look so different, its third-harmonic components are very similar, as expected theoretically. In Fig. 6 (b) and (d), the phasor representation for both cases is shown. As observed, the phase angle $\varphi$ has a positive and high value for healthy condition, and zero value for solid ground faults, as expected. The results for faults at $25 \%$ and $50 \%$ of the field winding can be observed in Fig. 7. As can be seen, the waveforms in these cases are totally different (Fig. 7 (a) and (c)), however, its third-harmonic components are very similar. In Fig. 7 (b) and (d), the phasor representation is presented for both cases. Here, an interesting fact has to be pointed out. For healthy condition (No Def), the value of the angle $\varphi$ is positive and high $\left(\varphi_{N F}\right)$, and identical for every case. However, in case of ground fault at $25 \%$ and $50 \%$ (Fig. 7 (b) and (d)), the angle for solid ground fault is slightly negative $\left(\varphi_{F}<0\right)$, while, in case of ground fault at $0 \%$ and $100 \%$ (Fig. 6 (b) and (d)), the angle for solid ground fault is zero $\left(\varphi_{F}=0\right)$. This fact is totally justified theoretically and it was previously described. The experimental results meet the expected results.

\section{Results with additional capacitance of $7.5 \mu \mathrm{F}$}

In order to evaluate the influence of the capacitance to ground in the detection algorithm, a second set of tests were conducted in the same synchronous machine. In this case, the value of capacitance to ground is $7.5 \mu \mathrm{F}$, which is considerably high. The rest of the conditions of the experimental setup remained identical, therefore the influence of the capacitance can be clearly observed.

In Fig. 8, the results of ground fault at $0 \%$ and $100 \%$ considering $7.5 \mu \mathrm{F}$ are shown. As observed, the waveforms at healthy condition for this value of capacitance to ground are different than in case of 1 $\mu \mathrm{F}$. However, as the value of fault resistance lowers, the waveform in both cases become $V_{n N}$ and $V_{p N}$ respectively (Fig. 8 (a) and (c)), as expected. The phasor representation of the voltages for these cases are presented in Fig. 8 (b) and (d). As can be seen, the value of $\varphi$ at healthy condition is positive, but lower than in the previous case $(1 \mu \mathrm{F})$. This fact is totally expected. As the capacitance to ground increases, the equivalent impedance at healthy condition is more resistive, and therefore the value of $\varphi_{N F}$ is lower. However, as the value of fault resistance lowers, the variable $\varphi$ goes to zero $\left(\varphi_{F}=0\right)$.

The results for faults at $25 \%$ and $50 \%$ of the field winding considering $7.5 \mu \mathrm{F}$ can be observed in Fig. 9. As can be observed in Fig. 9 (a) and (c), the waveforms are considerably different than in case of ground fault at $0 \%$ or $100 \%$. Nevertheless, its phasor representation (Fig. 9 (b) and (d)) shows that the value of $\varphi$ evolves as expected. Once again, the phase angle for solid ground fault at $25 \%$ and $50 \%$ (inner part of the winding) has a slightly negative value, as expected theoretically.

\section{Design criteria of $\boldsymbol{R}_{G}$}

The value of capacitance to ground has been shown to be a very influential parameter. It has to be taken into account when designing the grounding resistance. If the capacitance is high, the range of variation of $\varphi$ is small. This can make the detection algorithm being less sensitive. Since the value of capacitance to ground is given by each synchronous machine, it cannot be modified. However, the value of $R_{G}$ can be calculated in order to have a wide range of variation of $R_{G}$. Very high values of $R_{G}$ are not recommended because they limit too much the current in case of fault, and therefore it requires more accurate measurements. With this type of measurements, even small errors may imply unwanted trip commands of the detection algorithm. The proposed value of $R_{G}$ is such that makes $\varphi_{N F}$ being 60 degrees. See expression (7).

$$
R_{G} \approx \frac{1}{\left(\omega C_{R} \tan 60^{\circ}\right)}=\frac{1}{\left(\sqrt{3} \omega C_{R}\right)}
$$


(a)
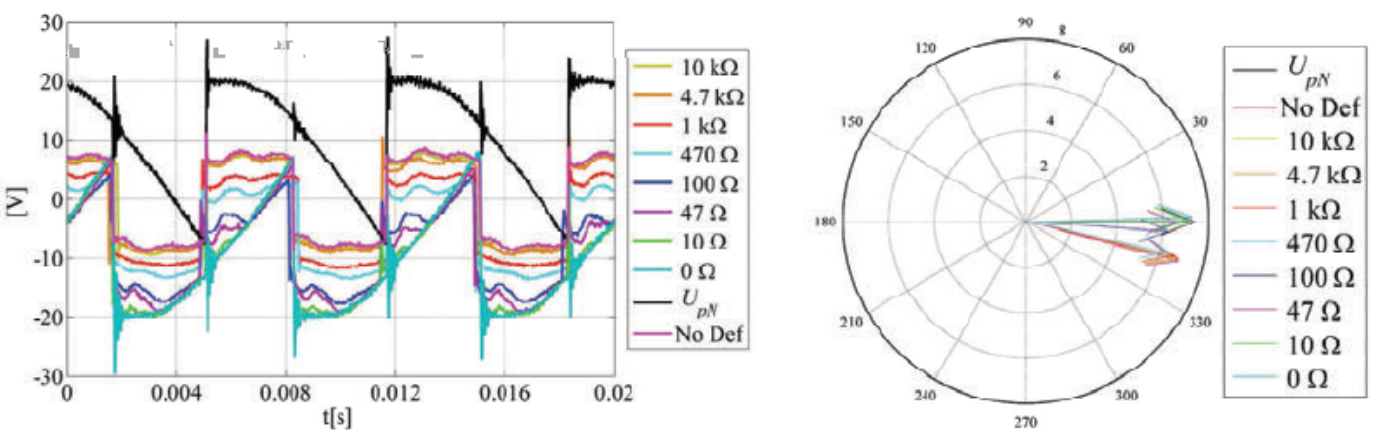

(b)

(c)
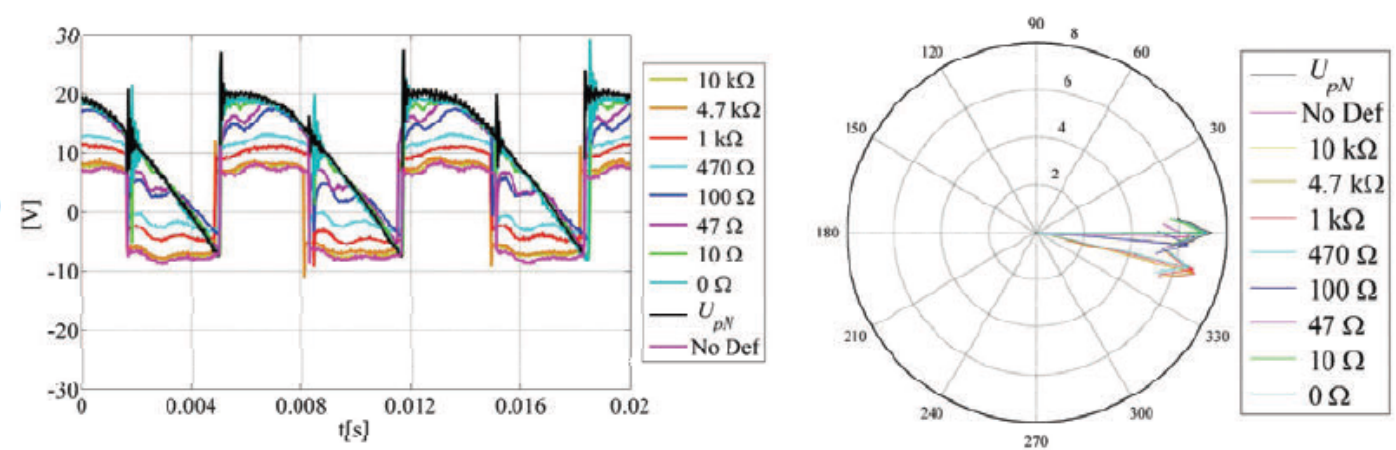

Fig. 8: Results of ground fault with several values of fault resistance. (a) Waveform of voltages for ground fault at $0 \%$; (b) phasor representation for ground fault at $0 \%$; (c) Waveform of voltages for ground fault at $100 \%$; (d) phasor representation for ground fault at $100 \%$. $C_{R}=7.5 \mu \mathrm{F}$.

(a)
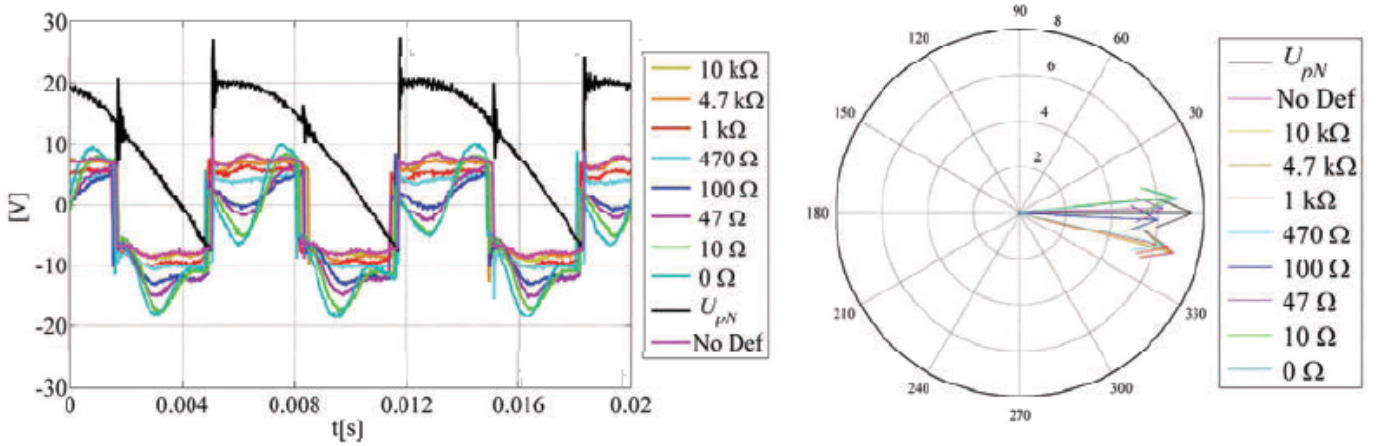

(b)

(c)
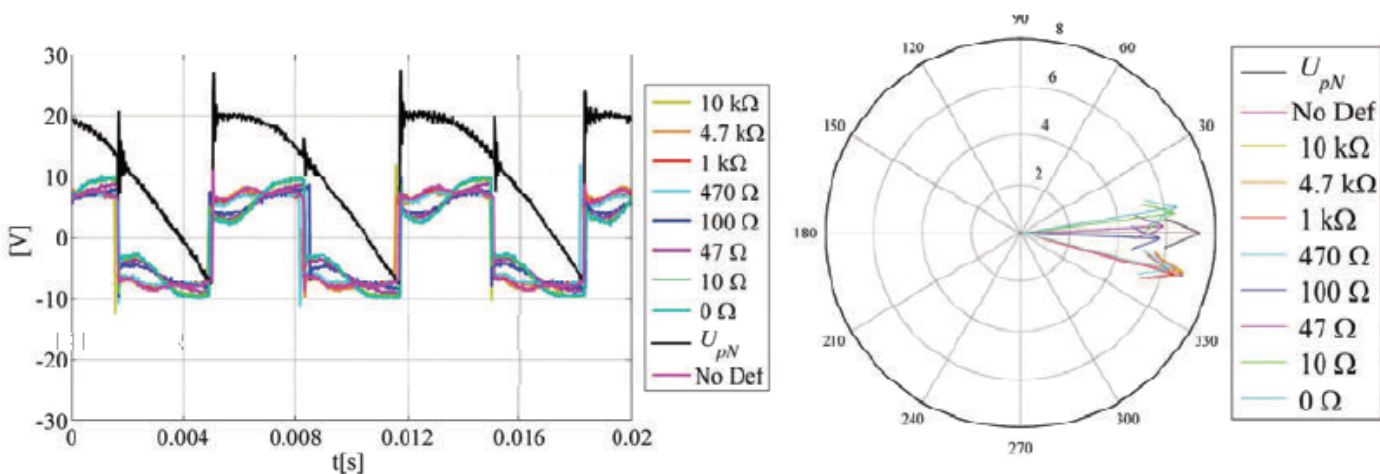

(d)

Fig. 9: Results of ground fault with several values of fault resistance. (a) Waveform of voltages for ground fault at $25 \%$; (b) phasor representation for ground fault at $25 \%$; (c) Waveform of voltages for ground fault at $50 \%$; (d) phasor representation for ground fault at $50 \%$. $C_{R}=7.5 \mu \mathrm{F}$. 


\section{Conclusions}

In this paper, a new ground-fault detection algorithm for field windings of synchronous machines has been presented. It is applicable to synchronous machines with static excitation and it requires a grounding resistor in the secondary winding of the excitation transformer. The detection algorithm is based on the comparison of the phase angle between two voltages. The reference phase angle is obtained from the voltage between the positive terminal and the neutral point. The second phase angle is obtained from the voltage measurement in the grounding resistor.

Firstly, a theoretical approach has been presented, in which the equivalent circuit of the static excitation system has been proposed. Secondly, the detection algorithm has been described. Finally, the algorithm has been tested in a 5kVA laboratory synchronous generator. Ground faults have been tested in several points of the winding and with several values of fault resistance, showing satisfactory results.

This detection algorithm may be interesting because of two advantages. First, its simplicity; it requires the supervision a single variable, the phase angle $\varphi$. Second, it does not need an external injection power supply for the fault detection, as the existing commercial protections do.

\section{References}

[1] “IEEE Guide for AC Generator Protection,” IEEE Std C37.102-2006 (Revison of IEEE Std C37.102-1995), Aug. 21, 2013, pp. 1-173.

[2] R.J. Zawosky \& W.M. Genoverse, "GER-3809: Generator Thermal Sensitivity, Theory and Experience", GE Power System, Schenectady, New York, Apr., 2001.

[3] Tetreault, A., "Rotor shape vs. rotor field pole shorted turns: Impact on rotor induced vibrations on hydrogenerators," in Proc. CMD, Sept. 23-27, 2012, pp. 133-136.

[4] Maughan, C.V.; Reschovsky, J.M., "Advances in motor and generator rotor health," in Proc. IEEE ISEI 2010, Jun. 6-9, 2010, pp. 1-4.

[5] Miller, M.L., "General concepts related to turbine generator insulation materials used in rotor windings," in Proc. IEEE EIC 2009, May 31-Jun. 3, 2009, pp. 328-332.

[6] Stone, G.C., "Recent important changes in IEEE motor and generator winding insulation diagnostic testing standards," IEEE Trans. Ind. Appl., vol. 41, no. 1, pp. 91-100, Jan.-Feb. 2005.

[7] Mollet, Y.; Gyselinck, J.; Meinguet, F., "Current sensor fault detection and isolation combining model-based and signal-based algorithms in PMSG drives," Power Electronics and Applications (EPE), 2013 15th European Conference on , vol., no., pp.1,10, 2-6 Sept. 2013

[8] Dinkhauser, V.; Fuchs, F.W., "Detection of rotor turn-to-turn faults in doubly-fed induction generators in wind energy plants by means of observers," Power Electronics and Applications, 2009. EPE '09. 13th European Conference on , vol., no., pp.1,10, 8-10 Sept. 2009

[9] Biet, M., "Rotor Faults Diagnosis Using Feature Selection and Nearest Neighbors Rule: Application to a Turbogenerator," IEEE Trans Ind. Electron., vol. 60, no. 9, pp. 4063-4073, Sept. 2013.

[10] Bacchus, A.; Biet, M.; Macaire, L.; Le Menach, Y.; Tounzi, A., "Comparison of supervised classification algorithms combined with feature extraction and selection: Application to a turbo-generator rotor fault detection," in Proc. IEEE SDEMPED, Aug. 27-30, 2013, pp. 558-565.

[11] Gaona, C. A. P.; Blázquez, F.; Frías, P.; Redondo, M., "A Novel Rotor Ground-Fault-Detection Technique for Synchronous MachinesWith Static Excitation,” IEEE Trans. Energy Convers., vol. 25, no. 4, pp. 965973, Dec. 2010.

[13] Blánquez, F.R.; Pardo, M.; Platero, C.A.; Rebollo, E.; Blázquez, F., "New on-line excitation-system groundfault location method tested in a 106 MVA synchronous generator," in Proc. IEEE ICEM, Sept. 2-5, 2014, pp. 1908--1914.

[13] "IEEE Guide for Diagnostic Field Testing of Electric Power Apparatus - Electrical Machinery," IEEE Std 62.2-2004, 2005, pp. $01-100$

[14] Platero, C.A.; Blázquez, F.; Frías, P.; Pardo, M., "New On-Line Rotor Ground Fault Location Method for Synchronous Machines With Static Excitation," IEEE Trans. Energy Convers., vol. 26, no. 2, pp. 572-580, June 2011.

[15] Blánquez, F.R.; Aranda, M.; Rebollo, E.; Blazquez, F.; Platero, C.A., "New Fault-Resistance Estimation Algorithm for Rotor-Winding Ground-Fault On-Line Location in Synchronous Machines with Static Excitation," Industrial Electronics, IEEE Transactions on , vol.PP, no.99, pp.1,1 